\title{
Diabetic Macular Edema With and Without Subfoveal Neuroretinal Detachment: Two Different Morphologic and Functional Entities
}

\author{
STELA VUJOSEVIC, TOMMASO TORRESIN, MARIANNA BERTON, SILVIA BINI, ENRICA CONVENTO, AND \\ EDOARDO MIDENA
}

- PURPOSE: To assess specific morphologic and functional characteristics in eyes with diabetic macular edema (DME) with subfoveal neuroretinal detachment $(\mathrm{SND}+)$ vs DME without SND (SND - ).

- DESIGN: Cross-sectional, prospective, comparative case series.

- METHODS: Seventy-two patients (72 eyes: 22 eyes SND + and 50 eyes SND-) with treatment-naïe, center-involving DME were evaluated. Data gathering included fundus color photographs, fluorescein angiography, spectral-domain optical coherence tomography (SD-OCT), best-corrected visual acuity (BCVA), and microperimetry. The following parameters were evaluated with SD-OCT: central macular thickness (CMT [including SND]); central retinal thickness (CRT [excluding SND]); choroidal thickness (CT); nasal and temporal retinal thickness (RT) at $500 \mu \mathrm{m}$ and $1500 \mu \mathrm{m}$ from the fovea; the number of hyperreflective retinal spots (HRS) in the central $3000 \mu \mathrm{m}$; and the presence of SND and integrity of the external limiting membrane (ELM). Retinal sensitivity (RS) was evaluated within 4 degrees and 12 degrees of the fovea. Correlation among CT, RS, and HRS in patients with and without SND was determined.

- RESUlTS: CMT $(P=.032)$, temporal RT at $1500 \mu \mathrm{m}$ $(P=.03)$, mean CT $(P=.009)$, and mean number of HRS $(P=.0001)$ were all higher in SND + vs SND eyes. CRT, BCVA, HbA1c, and prevalence of systemic arterial hypertension were not different between the 2 groups. RS within 4 degrees $(P=.002)$ and 12 degrees $(P=.015)$ was lower in SND+ vs SND - eyes. SND correlated significantly with disruption of the ELM $(54.55 \%$ vs $24 \%, P=.01)$ and lower RS. A direct correlation was found between the number of HRS, presence of SND, CT, and RS within 12 degrees in SND - eyes, and an inverse correlation was found between $\mathrm{CT}$ and $\mathrm{RS}$ within 12degrees in SND+ eyes.

Accepted for publication Jun 26, 2017.

From the Department of Ophthalmology, University of Padova, Padova, Italy (S.V., T.T., M.B., S.B., E.C., E.M.); and Fondazione G. B. Bietti, IRCCS, Rome, Italy (E.M.)

Inquiries to Edoardo Midena, Department of Ophthalmology, University of Padova, Via Giustiniani 2, 35128 Padova, Italy; e-mail: edoardo.midena@unipd.it
- CONCLUSIONS: These data may improve characterization of DME in eyes with SND. DME with SND correlates with greater CT, more HRS, disruption of the ELM, and significant macular functional impairment (RS decrease) vs SND-. (Am J Ophthalmol 2017;181:149-155. (C) 2017 Elsevier Inc. All rights reserved.)

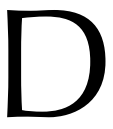
IABETIC MACULAR EDEMA (DME) PRESENTS WITH different patterns on optical coherence tomography (OCT), including sponge-like swelling, cystoid macular edema, and subfoveal neuroretinal detachment (SND). ${ }^{1}$ SND in DME is visible on OCT as a hypo-reflective area beneath the neuroretina and with a reported prevalence of approximately $15-30 \%$ in eyes with DME. ${ }^{1-5}$ Recently, higher concentrations of inflammatory cytokines in the vitreous and aqueous humor have been reported in eyes with SND, thus suggesting the presence of a significant inflammatory component. ${ }^{5-9}$ In particular, an increase in interleukin 6 (IL-6) has been associated with SND in DME. ${ }^{5}$ Some authors have reported a poorer visual prognosis after treatment of eyes with SND. ${ }^{10,11}$

Different hypotheses regarding the pathophysiology of SND have been postulated for this specific pattern of DME. ${ }^{1-4,12,13}$ Leakage from the retinal or choroidal circulation into the subretinal space that exceeds reabsorption capacity is thought to be the main mechanism. ${ }^{14}$ Several authors have reported retinal pigment epithelium (RPE) dysfunction in experimental and human diabetes, ${ }^{15-17}$ as RPE pumping capacity is decreased by hypoxia. ${ }^{18}$ Moreover, an impairment of choroidal blood flow, which may cause tissue hypoxia and RPE dysfunction, was reported in patients with DME. ${ }^{12}$ Also the integrity of the external limiting membrane (ELM) appears to contribute to the pathogenesis of SND. In fact, integrity of the ELM seems to be a key factor in preventing fluid from passing from the outer retina into subretinal space. ${ }^{2}$

The formation of SND is not associated with the duration or severity of DME. ${ }^{2}$ Otani and associates postulated that transient SND may represent fluid movement from the retina to the subretinal space during the process of macular edema absorption. ${ }^{10}$ Gaucher and associates reported 
that SND can occur very early in the genesis of DME, even before the accumulation of a large amount of fluid in the macula. ${ }^{2}$ SND may disappear either before or after the reabsorption of intraretinal fluid, thereby suggesting that SND is not associated with severe DME. ${ }^{2}$ Therefore, SND does not seem to be attributable to only the passive reabsorption of DME. ${ }^{2}$

Because little is known about the pathophysiology and the clinical characteristics of DME with SND, the main purpose of this study was to evaluate in detail morphologic and functional characteristics of patients with SND (SND+) and compare these to DME without SND (SND-).

\section{METHODS}

- POPUlATION: This is a cross-sectional, prospective, comparative, consecutive case series of 72 eyes (72 patients) with treatment-naïve, center-involving DME. All patients underwent a complete ophthalmologic examination with best-corrected visual acuity determination (BCVA), color fundus photographs, spectral-domain optical coherence tomography (SD-OCT), fluorescein angiography, and microperimetry. Exclusion criteria were any previous macular/retinal treatment (laser, intravitreal injections, and surgery), presence of macular traction on SD-OCT, history of uncontrolled glaucoma or ocular hypertension, and ischemic maculopathy. Informed consent was obtained from each patient and the research was carried out in accordance with the Declaration of Helsinki. Local Ethics Committee approval for the study was obtained.

- VISUAL ACUITY: BCVA was measured by a certified examiner using the standard Early Treatment Diabetic Retinopathy Study (ETDRS) protocol at a distance of 4 meters with a modified transilluminated ETDRS distance chart (Precision Vision, Bloomington, Illinois, USA). Visual acuity was scored as the total number of letters read correctly, calculated according to the ETDRS score method, and annotated in the clinical chart.

- SPECTRAL-DOMAIN OPTICAL COHERENCE TOMOGRAPHY: SD-OCT was performed with the Spectralis (Heidelberg Engineering, Heidelberg, Germany; Software 5.3.0.15), with the following scan patterns: 1 linear scan of $8.8 \mathrm{~mm}$ at 0 degrees centered on the fovea in High Speed mode and in Enhanced Depth Imaging (EDI) mode with a resolution of 100 automatic real time (ART), and a $6 \times$ 6 -mm macular map with resolution of 50 ART, centered on the fovea. Measurements made with the Heidelberg Eye Explorer software (EYEX) included the presence and height of SND, central macular thickness (CMT) (automatically measured within central $1 \mathrm{~mm}$ including also the SND), central retinal thickness (CRT; obtained excluding the SND, by measuring the SND height), and nasal and temporal thickness of the inner retina (IRT) and the outer retina (ORT) at $500 \mu \mathrm{m}$ and $1500 \mu \mathrm{m}$ from the fovea (IRT was measured from the inner limiting membrane to the outer plexiform layer).

The following parameters were also measured: ORT from the outer nuclear layer to the RPE; the total number of retinal hyperreflective spots (HRS) (calculated in the area of $3000 \mu \mathrm{m}$ centered on the fovea); integrity of the external limiting membrane (ELM) within the central $3 \mathrm{~mm}$; choroidal thickness measured at the fovea (foveal CT) and at $500 \mu \mathrm{m}$ and $1500 \mu \mathrm{m}$ from the fovea on the nasal and temporal side; and mean CT (mean value of 5 measured values: foveal CT, nasal and temporal CT at $500 \mu \mathrm{m}$ and $1500 \mu \mathrm{m}$ ) on linear B-scans obtained with EDI mode passing through the center of the fovea at 0 degrees (Figures 1 and 2).

- MICROPERIMETRY: Microperimetry was performed on all subjects using the MP1 Microperimeter (Nidek, Gamagori, Japan). The following standard parameters were used for DME patients: a fixation target consisting of a red ring, 1 degree in diameter; white, monochromatic background at 4 asb; stimulus size of Goldman III, with 200 ms projection time; customized radial grid of 45 stimuli covering the central 12 degrees (centered onto the fovea), 1 degree apart (inner stimuli) and 2 degrees apart (outer stimuli). ${ }^{19}$

The starting stimulus light attenuation was set at $10 \mathrm{~dB}$. A 4-2 double staircase strategy was used with an automatic eye tracker that compensates for eye movements. Pretest training was performed and 5-minute mesopic visual adaptation was allowed before starting the test. All subjects underwent microperimetry with dilated pupils. Mean retinal sensitivity (RS) was evaluated within the central 4 degrees and 12 degrees, approximately covering $1 \mathrm{~mm}$ and $3 \mathrm{~mm}$ of the central retina area on OCT mapping. ${ }^{19}$ Fixation stability and location were evaluated by the classification of Fujii and associates (stable, relatively unstable, and unstable; central, relatively eccentric, and eccentric fixation). ${ }^{20}$

- FLUORESCEIN ANGIOGRAPHY: Fluorescein angiography was performed with the Heidelberg Retinal Angiograph 2 (HRA 2; Heidelberg Engineering, Heidelberg, Germany). Angiography images were evaluated for the presence of significant retinal capillary dropout in the macula. All measurements were evaluated independently by 2 masked graders. In case of disagreement, a final adjudication was made by the senior retina specialist.

- STATISTICS: Fisher exact test was used to compare the prevalences of hypertension in SND+ and SND - patients. Mean HbA1c values were compared by Student $t$ test for independent samples. Mean values of CMT, CRT, retinal thickness (RT), CT, RS, and number of HRS were compared between groups by Student $t$ test for independent samples. The location and stability of fixation were 


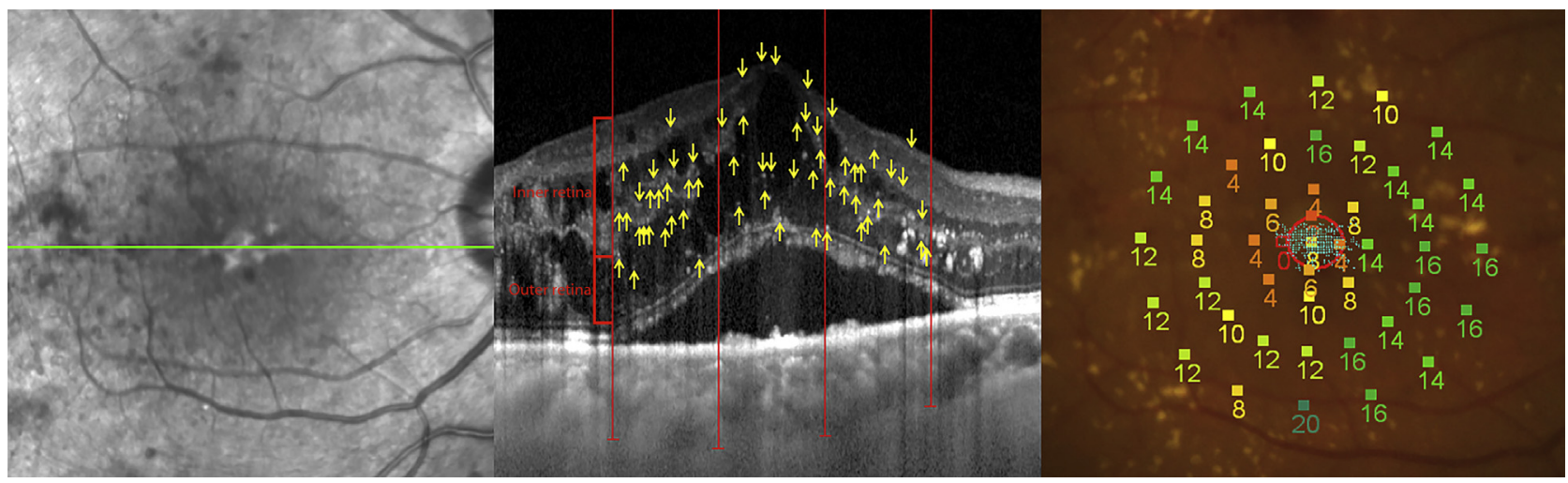

FIGURE 1. Right eye of a patient with diabetic macular edema and subfoveal neuroretinal detachment. (Left) Infrared reflectance image from spectral-domain optical coherence tomography (SD-OCT) image; green line indicates the position of the B-scan. (Middle) B-scan SD-OCT image obtained in the Enhanced Depth Imaging mode showing cystoid macular edema, subfoveal neuroretinal detachment, and numerous hyperreflective retinal spots (HRS) indicated with yellow arrows. The HRS were evaluated in the inner and outer retina within the central $3 \mathrm{~mm}$ (red vertical lines on OCT image delimit area within $3000 \mu \mathrm{m}$ ). (Right) Microperimetry map showing decreased retinal sensitivity and central and stable fixation.

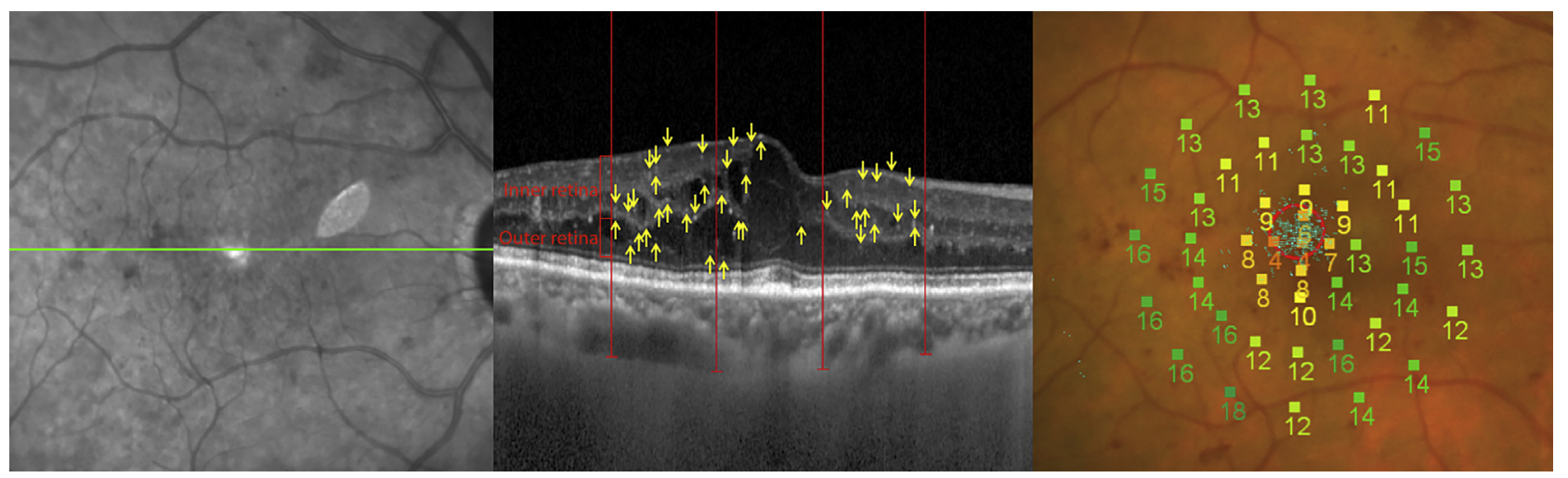

FIGURE 2. Right eye of a patient with cystoid diabetic macular edema. (Left) Infrared reflectance image from spectral-domain optical coherence tomography (SD-OCT) image; green line indicates the position of the B-scan. (Middle) B-scan SD-OCT image obtained in the Enhanced Depth Imaging mode showing cystoid macular edema; hyperreflective retinal spots (HRS) indicated with yellow arrows. The HRS were evaluated in the inner and outer retina within the central $3 \mathrm{~mm}$ (red vertical lines on OCT image delimit area within $3000 \mu \mathrm{m})$. (Right) Microperimetry map showing decreased retinal sensitivity and central and stable fixation.

evaluated by Fisher exact test. Correlation between the number of HRS and presence of SND was evaluated by a multiple logistic regression model with stepwise selection of determinants.

Spearman correlation coefficient was used to assess the correlation between CT and RS within 12 degrees, CT and number of HRS, RS within 12 degrees, and the number of HRS separately in SND - and SND+ eyes. A correlation coefficient of $>0.20$ was considered clinically relevant.

To test the effect of SND on the relationship between CT and RS, a linear regression model with CT as the dependent variable and $\mathrm{RS}$ as a covariate interacting with the SND subgroup was applied. A significant interaction term indicated that correlation between the 2 subgroups of patients was unequal. The same model was applied to the relationship between the HRS and RS, as well as HRS and CT. Because the distribution of these variables was skewed, the ranks of measurements, instead of original values, were used. Association between SND height and stability of fixation was evaluated by the Wilcoxon-Mann-Whitney test (normal approximation with continuity correction of 0.5 ). Correlations between ELM integrity and the presence and height of SND were evaluated by the $\chi^{2}$ and Wilcoxon-Mann-Whitney tests (normal approximation with continuity correction of $0.5)$, respectively.

For all statistical analyses, SAS 9.3 for personal computer statistical software (SAS Institute, Cary, North Carolina, USA) was used. $P$ values less than .05 were interpreted as statistically significant. 
TABLE 1. Morphologic Parameters of Study Eyes

\begin{tabular}{|c|c|c|c|}
\hline \multirow[b]{2}{*}{ Variable } & \multicolumn{2}{|c|}{ Subfoveal Neuroretinal Detachment } & \multirow[b]{2}{*}{$P$ Value $e^{a}$} \\
\hline & No & Yes & \\
\hline \multicolumn{4}{|l|}{ Macula thickness } \\
\hline СMT $(\mu \mathrm{m})$ & $499.5 \pm 116.7$ & $576.0 \pm 174.4$ & $.0320^{\star}$ \\
\hline $\mathrm{CRT}(\mu \mathrm{m})$ & $499.5 \pm 116.7$ & $460.6 \pm 145.6$ & .2315 \\
\hline \multicolumn{4}{|l|}{ Temporal RT } \\
\hline Inner $500 \mu \mathrm{m}$ & $256.9 \pm 77.9$ & $286.0 \pm 139.3$ & .2616 \\
\hline Outer $500 \mu \mathrm{m}$ & $181.8 \pm 69.9$ & $207.5 \pm 66.3$ & .1486 \\
\hline Total $500 \mu \mathrm{m}$ & $508.3 \pm 107.8$ & $566.4 \pm 161.0$ & .0759 \\
\hline Inner $1500 \mu \mathrm{m}$ & $229.2 \pm 51.5$ & $260.5 \pm 75.6$ & $.0442^{*}$ \\
\hline Outer $1500 \mu \mathrm{m}$ & $143.9 \pm 72.5$ & $172.4 \pm 64.3$ & .1168 \\
\hline Total $1500 \mu \mathrm{m}$ & $430.3 \pm 117.5$ & $500.9 \pm 130.7$ & $.0264^{*}$ \\
\hline \multicolumn{4}{|l|}{ Nasal RT } \\
\hline Inner $500 \mu \mathrm{m}$ & $243.4 \pm 81.3$ & $271.1 \pm 83.5$ & .1913 \\
\hline Outer $500 \mu \mathrm{m}$ & $159.5 \pm 71.8$ & $159.3 \pm 53.3$ & .9925 \\
\hline Total $500 \mu \mathrm{m}$ & $480.8 \pm 113.9$ & $530.3 \pm 139.0$ & .1176 \\
\hline Inner $1500 \mu \mathrm{m}$ & $233.6 \pm 46.9$ & $253.8 \pm 77.5$ & .1751 \\
\hline Outer $1500 \mu \mathrm{m}$ & $101.3 \pm 41.5$ & $130.2 \pm 61.8$ & $.0228^{\star}$ \\
\hline Total $1500 \mu \mathrm{m}$ & $411.7 \pm 84.5$ & $446.8 \pm 70.3$ & .0926 \\
\hline \multicolumn{4}{|l|}{ Choroidal thickness } \\
\hline Fovea & $206.5 \pm 57.4$ & $238.4 \pm 52.2$ & $.0285^{\star}$ \\
\hline Temporal $500 \mu \mathrm{m}$ & $205.3 \pm 58.6$ & $230.9 \pm 52.7$ & .1102 \\
\hline Temporal $1500 \mu \mathrm{m}$ & $198.0 \pm 60.6$ & $230.8 \pm 60.2$ & .0841 \\
\hline Nasal $500 \mu \mathrm{m}$ & $200.9 \pm 60.3$ & $224.5 \pm 48.4$ & $.0003^{*}$ \\
\hline Nasal $1500 \mu \mathrm{m}$ & $170.9 \pm 48.7$ & $222.0 \pm 60.3$ & $.0378^{\star}$ \\
\hline Total & $196.3 \pm 48.9$ & $229.3 \pm 48.0$ & $.0098^{\star}$ \\
\hline HRS & $79.7 \pm 22.8$ & $100.6 \pm 12.2$ & $<.0001^{\star}$ \\
\hline \multicolumn{4}{|c|}{$\begin{array}{l}\text { CMT = central macular thickness; CRT }=\text { central retinal thick- } \\
\text { ness excluding subfoveal neuroretinal detachment; } \\
\text { HRS = hyperreflective retinal spots; Inner }=\text { inner retinal thick- } \\
\text { ness from the inner limiting membrane to the outer plexiform } \\
\text { layer; Outer = outer retinal thickness from the outer nuclear layer } \\
\text { to the retinal pigment epithelium; RT = retinal thickness; } \\
\text { Total = mean value from all measured points. } \\
\text { Asterisk }\left(^{*}\right) \text { indicates statistically significant } P \text { value. } \\
{ }^{a} t \text { test for independent samples. }\end{array}$} \\
\hline
\end{tabular}

\section{RESULTS}

- DEMOGRAPHICS: A total of 72 eyes of 72 patients were evaluated; 22 eyes were SND+ and 50 eyes were SND-. There was no significant difference in mean HbA1c levels and systemic arterial hypertension between SND+ and SND- patients $(7.4 \%$ vs $7.5 \%, P=.71 ; P=.27$, Fisher exact test).

- COMPARISONS BETWEEN OPTICAL COHERENCE TO. MOGRAPHY MEASUREMENTS AND SUBFOVEAL NEURORETINAL DETACHMENT: Mean values of CMT (including SND), CRT (excluding SND), inner and outer RT at $500 \mu \mathrm{m}$ and $1500 \mu \mathrm{m}$ from the fovea both at the nasal and the temporal side, CT, and number of HRS are listed in Table 1. CMT, foveal CT, and mean CT were significantly higher in SND+ eyes vs SND- eyes
TABLE 2. Functional Parameters of Study Eyes

\begin{tabular}{|c|c|c|c|}
\hline \multirow[b]{2}{*}{ Variable } & \multicolumn{2}{|c|}{$\begin{array}{l}\text { Subfoveal Neuroretinal } \\
\text { Detachment }\end{array}$} & \multirow[b]{2}{*}{$P$ Value } \\
\hline & No & Yes & \\
\hline $\begin{array}{l}\text { BCVA (ETDRS letters, } \\
\text { mean } \pm \text { SD) }\end{array}$ & $59.0 \pm 13.8$ & $55.8 \pm 12.4$ & $.3434^{a}$ \\
\hline $\begin{array}{l}\text { Retinal sensitivity } 4 \text { degrees } \\
\quad(\mathrm{dB}, \text { mean } \pm \mathrm{SD})\end{array}$ & $10.0 \pm 4.4$ & $4.5 \pm 4.4$ & $.0024^{a \star}$ \\
\hline $\begin{array}{l}\text { Retinal sensitivity } 12 \text { degrees } \\
\quad(\mathrm{dB}, \text { mean } \pm \mathrm{SD})\end{array}$ & $12.8 \pm 3.9$ & $8.7 \pm 5.0$ & $.0152^{a \star}$ \\
\hline $\begin{array}{l}\text { Site of fixation, number (\%) } \\
\text { of patients }\end{array}$ & & & $.1902^{b}$ \\
\hline Central & $48(96 \%)$ & $18(81.8 \%)$ & \\
\hline Relatively eccentric & $2(4 \%)$ & $4(18.2 \%)$ & \\
\hline $\begin{array}{l}\text { Fixation stability, number (\%) } \\
\text { of patients }\end{array}$ & & & $.0035^{b *}$ \\
\hline Unstable & $4(8 \%)$ & $0(0 \%)$ & \\
\hline Relatively unstable & $4(8 \%)$ & $13(59.1 \%)$ & \\
\hline Stable & $42(84 \%)$ & $9(40.9 \%)$ & \\
\hline \multicolumn{4}{|c|}{$\begin{array}{l}\text { BCVA }=\text { best-corrected visual acuity; SD }=\text { standar } \\
\text { tion. } \\
\text { Asterisk }\left(^{\star}\right) \text { indicates statistically significant } P \text { value. } \\
{ }^{a} \text { Student } t \text { test for independent samples. } \\
{ }^{b} \text { Fisher exact test. }\end{array}$} \\
\hline
\end{tabular}

$(P=.0320, P=.0285$, and $P=.0098$, respectively $)$. CRT was not different between SND+ eyes and SNDeyes $(P=.2315)$. The number of HRS was significantly higher in SND+ than SND - eyes $(P<.0001)$.

Table 2 shows the mean values of the following functional parameters: BCVA, RS within the central 4 degrees and 12 degrees, and fixation characteristics (fixation stability and location). RS was lower in SND+ eyes both within the central 4 degrees $(P=.0024)$ and 12 degrees $(P=.0152)$. There was a significant difference in fixation stability between SND+ and SND- eyes $(P=.0035)$. Fixation was predominantly central in both groups.

A direct and statistically significant correlation was found between the number of HRS and the presence of SND (odds ratio $=1.05 ; 95 \%$ confidence limits 1.01 . 1.09; $P=.017)$.

Results in Table 3 show a statistically significant correlation between mean CT in the macula and RS within 12 degrees in SND- eyes (Spearman correlation, rho = $0.455, P=.022$ ), whereas an inverse, although not statistically significant, correlation was seen in SND+ eyes (Spearman correlation, rho $=-0.365, P=.300$ ). HRS were inversely correlated to RS in SND- eyes (Spearman correlation, rho $=-0.415, P=.039$ ), but no significant correlation was found between HRS and RS in SND+ eyes.

Mean SND height was $115 \mu \mathrm{m}$ (median: $99 \mu \mathrm{m}$; range: 20-280 $\mu \mathrm{m}$ ). Table 4 shows the correlation between SND height and morphologic parameters (mean CT, CMT, and 
TABLE 3. Spearman Correlation Coefficients Among Choroidal Thickness, Retinal Sensitivity Within Central 12 Degrees, and Hyperreflective Retinal Spots in Patients With and Without Subfoveal Neuroretinal Detachment

\begin{tabular}{ccr}
\hline & RS 12 Deg & Total Number of HRS \\
\hline Patients without SND & & \\
Choroidal thickness & $0.455^{a *}(.022)$ & $-0.262^{b *}(.066)$ \\
RS 12 deg & & $-0.415^{c *}(.039)$ \\
Patients with SND & & \\
Choroidal thickness & $-0.365^{\star}(.300)$ & $-0.097(.667)$ \\
RS 12 deg & & $0.198(.583)$ \\
\hline
\end{tabular}

HRS = hyperreflective retinal spots; RS 12 deg = retinal sensitivity within 12 central degrees; SND = subfoveal neuroretinal detachment.

Clinically significant coefficients (rho $>0.20$ ) are designated by an asterisk $\left({ }^{\star}\right) . P$ value of the statistical test in parentheses.

${ }^{a}$ Effect of SND on the relationship between choroidal thickness and retinal sensitivity: $P=.003$.

${ }^{b}$ Effect of SND on the relationship between total number of HRS and choroidal thickness: $P=.443$.

${ }^{c}$ Effect of SND on the relationship between total number of HRS and retinal sensitivity: $P=.003$.

CRT) and functional parameters (BCVA, RS within 4 degrees and 12 degrees). SND height was inversely correlated only to RS. In addition, SND height was not correlated to the stability of fixation (Wilcoxon-Mann-Whitney test, $P=1.000)$.

- EXTERNAL LIMITING MEMBRANE: The ELM was intact in 48 eyes and disrupted in 24 eyes. In the group of SND+ eyes, the ELM was intact in $10(45.45 \%)$ and disrupted in $12(54.55 \%)$, whereas in the group of SNDeyes, ELM was intact in $38(76.0 \%)$ and disrupted in 12 (24.0\%). The presence of SND was significantly correlated with disruption of the ELM (54.55\% vs $24.0 \%$; $\chi^{2}$ test, $P=$ $.0113)$. Moreover, the mean height of the SND was greater in eyes with disrupted ELM vs eyes with intact ELM (141.3 $\mu \mathrm{m}$ vs $84.4 \mu \mathrm{m}, P=.051)$.

\section{DISCUSSION}

IN THIS STUDY WE EVALUATED AND COMPARED SPECIFIC morphologic and functional characteristics of patients with treatment-naïve, center-involving DME, with and without SND. More specifically, CMT, CRT, inner and outer RT, HRS, and CT as morphologic parameters and BCVA, RS, and fixation characteristics (determined by microperimetry) as functional parameters were evaluated.

The main reason to evaluate these specific features was to obtain more information on, and better understand, the clinical characteristics of eyes with SND owing to DME. In the present study SND was seen in 22 of 72 eyes
TABLE 4. Correlation Between Subfoveal Neuroretinal Detachment Thickness and Morphologic and Functional Parameters

\begin{tabular}{lllllll}
\hline & Total CT & CMT & CRT & BCVA & RS 4 Deg & RS 12 Deg \\
\hline $\begin{array}{c}\text { Spearman } \\
\text { correlation } \\
\text { coefficient }\end{array}$ & -0.144 & 0.186 & 0.035 & -0.341 & $-0.394^{\text {a* }}$ & $-0.497^{\text {b* }}$ \\
\hline
\end{tabular}

BCVA = best-corrected visual acuity; CMT = central macular thickness; CRT = central retinal thickness excluding subfoveal neuroretinal detachment; RS 4 Deg = retinal sensitivity within central 4 degrees; RS 12 Deg = retinal sensitivity within central 12 degrees; Total $\mathrm{CT}=$ mean choroidal thickness (mean value from all measured points).

Clinically significant coefficients are designated by an asterisk $\left(^{*}\right)$.

${ }^{a} P=.070$ borderline.

${ }^{b} P=.019$.

$(30.5 \%)$, which is in line with previous reports. ${ }^{2-4}$ The major difference in RT between SND+ and SND- eyes was found in the CMT, whereas there was no significant difference in CRT and inner or outer retinal thickness (IRT, ORT) in the perifoveal region. Because there was no difference in the CRT between SND+ and SNDeyes, the difference in CMT measurements is attributable to the presence of subretinal fluid (extracellular fluid pooling between the outer segments of the photoreceptors and RPE). In this cohort of patients there was no significant difference in intraretinal thickness.

The choroid was significantly thicker in SND+ eyes vs SND - eyes, both in the fovea and in the nasal perifoveal area. Data in the literature regarding CT in eyes with DME are conflicting. Whereas most authors report a decrease or no change in CT in eyes with DME, ${ }^{12,21-26}$ others report an increase in CT in DME eyes. ${ }^{27,28} \mathrm{Kim}$ and associates reported increased subfoveal choroidal thickness in eyes with DME and SND compared to DME without SND. ${ }^{28}$ This was confirmed in the present study. Thus, the present data may indicate that differences in DME and CT patterns may be attributed to different populations. Data from the present study (increased CT in treatment-naïve DME eyes associated with SND) confirm the hypothesis by Campos and associates that SND is more likely to occur in early-onset DME associated with increased CT, increased choriocapillaris permeability, and outer blood-retinal barrier (BRB) dysfunction. ${ }^{29}$ Therefore, the association of CT with different DME patterns merits further study.

In this study glycemic control and arterial hypertension did not correlate with the presence of SND, thus suggesting that local (intraocular) factors might be more important to the development of SND.

The pathophysiology by which SND forms is not yet fully understood, but one of the proposed mechanisms includes the condition of the ELM. ${ }^{4}$ Breakdown of the inner 
BRB in eyes with DME causes an extravasation of lipids and proteins, but proteins and cells have difficulty passing through an intact ELM. Thus, they accumulate anterior to the ELM, resulting in swelling of the outer retina. When the ELM is compromised, proteins and fluid in the outer retina may move more easily into the subretinal space. These changes result in the development of SND. ${ }^{1}$ Data from the present study confirm this, where disrupted ELM is correlated with the presence and height of SND in eyes with DME.

Disruption of the ELM in eyes with DME can be accompanied by cell damage, which attracts scavenger cells to the retina. These cells may be a source of IL-6. ${ }^{1,6}$ In fact, SND has been correlated with higher intravitreal levels of IL-6, thus indicating a heightened "inflammatory condition." Increased concentrations of inflammatory cytokines and chemokines have been reported in the vitreous and aqueous humor of patients with DME., ${ }^{5,30,31}$ Increased synthesis of cytokines by activated retinal glial cells results in elevated aqueous humor concentrations, even during the early stages of DR. ${ }^{30}$

HRS on SD-OCT have been proposed as clinical signs of activated microglial cell aggregates in the retina. ${ }^{19,32-35}$ The HRS, proposed as an imaging biomarker of retinal inflammation in eyes with DME, have the following characteristics: small size $(<30 \mu \mathrm{m})$; reflectivity similar to the nerve fiber layer; located in both the inner and outer but mostly in the outer retina; and no backshadowing. These characteristics have been studied and validated previously. ${ }^{35}$ The present study confirms previously published data that showed a significant increase in the number of HRS in SND+ eyes vs SND- eyes. ${ }^{19}$ Moreover, in the present study a direct and significant correlation was found between the HRS number and the presence of SND, thus strengthening the hypothesis of a "major inflammatory condition" in this pattern of DME.
Functional parameters (RS and fixation stability), showed greater visual impairment in SND+ eyes vs SND- eyes. Moreover, a greater SND height correlated with decreased RS. Deák and associates reported that SND and large cysts in the outer nuclear layer are the 2 morphologic changes with the greatest negative impact on RS in DME. ${ }^{36}$ Seo and associates reported no differences in BCVA based on different OCT patterns (cystoid, diffuse, and with SND) at baseline, but only the SND type had a poorer functional response after anti-VEGF treatment. ${ }^{11}$ In the present study there was no difference in BCVA between SND+ eyes and SND- eyes.

An inverse correlation was found between choroidal thickness and RS in SND+ eyes, whereas a direct correlation was found between CT and RS in SND- eyes. This is a peculiar finding that probably indicates that DME with SND+ and SND - are 2 different morphologic and functional entities. Although no final conclusions can be drawn (owing to the limited number of examined eyes and no longitudinal data), it suggests that different patterns of DME that can be easily visualized with noninvasive imaging instruments such as SD-OCT should be more closely evaluated. The role of the choroid in DME may be related to the nature of the "retinal inflammatory condition" and may determine the morphologic pattern of DME, such as the presence of SND. Also the integrity of the ELM should be evaluated in SND+ eyes, because its disruption may indicate a poorer functional outcome. Moreover, functional impairment (RS) in eyes with SND+ and SND - may indicate the importance of the choroid on RS and fixation deterioration, and not just the presence of retinal edema. A longitudinal study evaluating these specific characteristics in relation to local treatment might provide more information on therapeutic outcomes in different patterns of DME, particularly those with SND.

FUNDING/SUPPORT: NO FUNDING OR GRANT SUPPORT. FINANCIAL DISCLOSURES: THE FOLLOWING AUTHORS HAVE NO financial disclosures: Stela Vujosevic, Tommaso Torresin, Marianna Berton, Silvia Bini, Enrica Convento, and Edoardo Midena. All authors attest that they meet the current ICMJE criteria for authorship.

Other Acknowledgments: The authors thank Fabiano Cavarzeran, ScD, from the Department of Neuroscience, University of Padova, Padova, Italy for his help in the statistical analyses of the data.

\section{REFERENCES}

1. Otani T, Kishi S, Maruyama Y. Patterns of diabetic macular edema with optical coherence tomography. Am J Ophthalmol 1999;127(6):688-693.

2. Gaucher D, Sebah C, Erginay A, et al. Optical coherence tomography features during the evolution of serous retinal detachment in patients with diabetic macular edema. Am J Ophthalmol 2008;145(2):289-296.

3. Catier A, Tadayoni R, Paques M, et al. Characterization of macular edema from various etiologies by optical coherence tomography. Am J Ophthalmol 2005;140(2):200-206.
4. Ozdemir H, Karacorlu M, Karacorlu S. Serous macular detachment in diabetic cystoid macular oedema. Acta Ophthalmol Scand 2005;83(1):63-66.

5. Sonoda S, Sakamoto T, Yamashita T, Shirasawa M, Otsuka H, Sonoda Y. Retinal morphologic changes and concentrations of cytokines in eyes with diabetic macular edema. Retina 2014;34(4):741-748.

6. Funatsu H, Yamashita H, Noma H, Mimura T, Yamashita T, Hori S. Increased levels of vascular endothelial growth factor and interleukin-6 in the aqueous humor of diabetics with macular edema. Am J Ophthalmol 2002; 133(1):70-77. 
7. Funatsu H, Yamashita H, Sakata K, et al. Vitreous levels of vascular endothelial growth factor and intercellular adhesion molecule 1 are related to diabetic macular edema. Ophthalmology 2005;112(5):806-816.

8. Funatsu H, Noma H, Mimura T, Eguchi S, Hori S. Association of vitreous inflammatory factors with diabetic macular edema. Ophthalmology 2009;116(1):73-79.

9. Sohn HJ, Han DH, Kim IT, et al. Changes in aqueous concentrations of various cytokines after intravitreal triamcinolone versus bevacizumab for diabetic macular edema. Am J Ophthalmol 2011;152(4):686-694.

10. Otani T, Kishi S. Tomographic assessment of vitreous surgery for diabetic macular edema. Am J Ophthalmol 2000;129(4): 487-494.

11. Seo KH, Yu SY, Kim M, Kwak HW. Visual and morphologic outcomes of intravitreal ranibizumab for diabetic macular edema based on optical coherence tomography patterns. Retina 2016;36(3):588-595.

12. Nagaoka T, Kitaya N, Sugawara R, et al. Alteration of choroidal circulation in the foveal region in patients with type 2 diabetes. Br J Ophthalmol 2004;88(8):1060-1063.

13. Marmor MF. Control of subretinal fluid and mechanisms of serous detachment. In: Marmor MF, Wolfensberger TJ, eds. The Retinal Pigment Epithelium: Function and Disease. New York, NY: Oxford University Press; 1998:420-437.

14. Weinberg D, Jampol LM, Schatz H, Brady KD. Exudative retinal detachment following central and hemicentral retinal vein occlusions. Arch Ophthalmol 1990;108(2):271-275.

15. Kirber WM, Nichols CW, Grimes PA, Winegrad AI, Laties AM. A permeability defect of the retinal pigment epithelium. Occurrence in early streptozocin diabetes. Arch Ophthalmol 1980;98(4):725-728.

16. Grimes PA, Laties AM. Early morphological alteration of the pigment epithelium in streptozotocin-induced diabetes: increased surface area of the basal cell membrane. Exp Eye Res 1980;30(6):631-639.

17. Weinberger D, Fink-Cohen S, Gaton DD, Priel E, Yassur Y. Non-retinovascular leakage in diabetic maculopathy. $\mathrm{Br} \mathrm{J}$ Ophthalmol 1995;79(8):728-731.

18. Spaide R, Yannuzzi L. Manifestations and pathophysiology of serous detachment of the retinal pigment epithelium and retina. In: Marmor M, Wolfensberger $\mathrm{T}$, eds. The Retinal Pigment Epithelium: Function and Disease. New York, NY: Oxford University Press; 1998:439-455.

19. Vujosevic S, Torresin T, Bini S, et al. Imaging retinal inflammatory biomarkers after intravitreal steroid and anti-VEGF treatment in diabetic macular oedema. Acta Ophthalmol 2016;95(5):464-471.

20. Fujii GY, De Juan E Jr, Sunness J, et al. Patient selection for macular translocation surgery using the scanning laser ophthalmoscope. Ophthalmology 2002;109(9):1737-1744.

21. Querques G, Lattanzio R, Querques L, et al. Enhanced depth imaging optical coherence tomography in type 2 diabetes. Invest Ophthalmol Vis Sci 2012;53(10):6017-6024.

22. Regatieri CV, Branchini L, Carmody J, Fujimoto JG, Duker JS. Choroidal thickness in patients with diabetic retinopathy analyzed by spectral-domain optical coherence tomography. Retina 2012;32(3):563-568.
23. Adhi M, Brewer E, Waheed NK, Duker JS. Analysis of morphological features and vascular layers of choroid in diabetic retinopathy using spectral-domain optical coherence tomography. JAMA Ophthalmol 2013;131(10): 1267-1274.

24. Vujosevic S, Martini F, Cavarzeran F, Pilotto E, Midena E. Macular and peripapillary choroidal thickness in diabetic patients. Retina 2012;32(9):1781-1790.

25. Lee HK, Lim JW, Shin MC. Comparison of choroidal thickness in patients with diabetes by spectral-domain optical coherence tomography. Korean J Ophthalmol 2013;27(6): 433-439.

26. Esmaeelpour M, Považay B, Hermann B, et al. Mapping choroidal and retinal thickness variation in type 2 diabetes using three-dimensional 1060-nm optical coherence tomography. Invest Ophthalmol Vis Sci 2011;52(8):5311-5316.

27. Hua R, Liu L, Wang X, Chen L. Imaging evidence of diabetic choroidopathy in vivo: angiographic pathoanatomy and choroidal-enhanced depth imaging. PLoS One 2013;8(12): e83494.

28. Kim JT, Lee DH, Joe SG, Kim JG, Yoon YH. Changes in choroidal thickness in relation to the severity of retinopathy and macular edema in type 2 diabetic patients. Invest Ophthalmol Vis Sci 2013;54(5):3378-3384.

29. Campos A, Campos EJ, Martins J, Ambrósio AF, Silva R. Viewing the choroid: where we stand, challenges and contradictions in diabetic retinopathy and diabetic macular oedema. Acta Ophthalmol 2017;95(5):446-459.

30. Vujosevic S, Micera A, Bini S, Berton M, Esposito G, Midena E. Proteome analysis of retinal glia cells-related inflammatory cytokines in the aqueous humour of diabetic patients. Acta Ophthalmol 2016;94(1):56-64.

31. Dong N, Xu B, Chu L, Tang X. Study of 27 aqueous humor cytokines in type 2 diabetic patients with or without macular edema. PLoS One 2015;10(4):e0125329.

32. Coscas G, De Benedetto U, Coscas F, et al. Hyperreflective dots: a new spectral-domain optical coherence tomography entity for follow-up and prognosis in exudative age-related macular degeneration. Ophthalmologica 2013;229(1):32-37.

33. Vujosevic S, Bini S, Midena G, Berton M, Pilotto E, Midena E. Hyperreflective intraretinal spots in diabetics without and with nonproliferative diabetic retinopathy: an in vivo study using spectral domain OCT. J Diabetes Res 2013;2013:491835.

34. Vujosevic S, Berton M, Bini S, Casciano M, Cavarzeran F, Midena E. Hyperreflective retinal spots and visual function after anti-vascular endothelial growth factor treatment in center-involving diabetic macular edema. Retina 2016; 36(7):1298-1308.

35. Vujosevic S, Bini S, Torresin T, et al. Hyperreflective retinal spots in normal and diabetic eyes: B-scan and en face spectral domain optical coherence tomography evaluation. Retina 2017;37(6):1092-1103.

36. Deák GG, Bolz M, Ritter M, Prager S, Benesch T, SchmidtErfurth U. Diabetic Retinopathy Research Group Vienna. A systematic correlation between morphology and functional alterations in diabetic macular edema. Invest Ophthalmol Vis Sci 2010;51(12):6710-6714. 